\title{
Using Social Network Analysis to Evaluate Academic Assistance Networks in a Holistic Education Secondary School
}

\author{
R. Renee Setari and Anthony P. Setari \\ University of Kentucky \\ Keywords: social network analysis, Montessori, Erdkinder, evaluation, holistic education
}

\begin{abstract}
One goal of Erdkinder schools is for students and teachers to provide academic assistance to their peers, particularly to less-knowledgeable ones. However, traditional educational evaluations do not provide a means to investigate the exchange of academic help. This study piloted the use of social network analysis to describe academic assistance relationships within a Montessori secondary school. Using a network survey, social network data concerning the exchange of academic help were collected from 23 students and 8 teachers. The results show that while students provide help to both fellow students and teachers, teachers are the main source of assistance for students. In some subjects, a few students and teachers neither provided nor received assistance, indicating another area for improvement. The results of a multiple regression quadratic assignment procedure (multiple regression-QAP) show that for most subjects, their willingness to help others was not significantly influenced by their own personal level of knowledge. Thus, moreknowledgeable individuals do not provide more assistance to less-knowledgeable peers. To adhere to Erdkinder principles, this school should encourage more-knowledgeable students to recognize their responsibility to help others and to actually help those who need support. This pilot yielded valuable information, and social network analysis warrants further study within holistic education.
\end{abstract}

Montessori high schools, known as Erdkinders, are a form of holistic education that has experienced a recent resurgence in the number of active schools (Barker, 2011; Kahn, 2011; R. Miller, 1990). One goal of Erdkinders is to promote the development of adolescents beyond cognitive development. Similar to many other forms of holistic education, the Erdkinder system is designed to provide students with an educational experience that fosters independence in an environment where they can develop their talents, support each other, and work as equals with their teachers and peers (Montessori, 1973). These schools educate students in cognitive, social, emotional, and moral development, toward the development of the whole child (R. Miller, 1990; J. P. Miller, 2010). Such intentions have allowed these and other types of holistic schooling to become more popular in the United States, as more parents seek these environments for their children (Forbes \& Martin, 2004). However, Erdkinders, and other holistic education schools attempting to build similar environments, have few options for evaluating whether they are actually developing the supportive and egalitarian environment they seek to implement. 


\section{A Review of the Literature}

\section{Adolescents and Montessori Schooling}

Although Maria Montessori's work is primarily associated with early childhood education, she also included adolescent education in her conceptualization of human development (Grazzini, 2004; Gutek, 2004; Standing, 1998). Dr. Montessori asserted that adolescents experience the same level of physical and emotional turmoil they experienced as infants and that they need particular support as they engage with society and one another (Montessori, 2011c). She had two primary concerns for the adolescent years: to protect children during this sensitive time in life and to support them in developing the skills to understand their role in society (Barker, 2011). The eventual goal of adolescence was a healthy transition to young adulthood and support of the adolescent's valorization, which Donahoe (2010) described as "the adolescent's process of becoming a strong and worthy person” (p. 1).

Dr. Montessori wanted adolescents' educational experience to take place at an Erdkinder, a boarding school in a farm setting, allowing students to specialize in tasks and trade services (Montessori, 1973). Students learn through their experiences on the farm-for example, learning biology through agricultural food production - and do not attend classes in a traditional format. When students live and work on an Erdkinder, Dr. Montessori believed they develop the skills that assure they are independent and productive contributors to a peaceful society (Montessori, 1973; Montessori, 2011a; Montessori, 2011b; Tornar, 2011).

\section{Academic Assistance in Erdkinder}

Dr. Montessori considered work important in personality development in adolescents and in children of other ages. Schoolwork needs to provide students with the opportunity to learn self-sufficiency, as well as the experience of identifying challenges to their community and of working to address those challenges as a positive force (Montessori, 1973; Montessori, 2011a; Tornar, 2011). By working together and helping others at Erdkinders, students gain not only the benefit of the knowledge imparted from completing a task, but also learn how they can help others through their work and appreciate the value of their own ability to reach a goal or complete a task (Kahn, 2011; Kahn \& Pendleton, 2007). In time, a student should come to offer assistance to others in need of a skill that the student possesses, regardless of whether it is part of an assigned task (Kahn, 2011; Montessori, 1973). This helpfulness - the ability to identify problems and the willingness to offer assistance-is an action that specifically supports students' valorization process (Donahoe, 2010). Thus, a goal of Erdkinder schooling is to cultivate helpfulness in adolescents as one way to support the valorization process.

It is important to note that although highly skilled and knowledgeable students within a school should provide a great deal of help to others, specifically to those lacking these skills and knowledge, these students should not be seen by others within the school as a knowledgeable elite. Instead, individuals should share the responsibility of supporting the community, regardless of any perception that they are highly skilled or knowledgeable; everyone should assist others because everyone has unique abilities that can be used to support others (Kahn, 2011; Montessori, 1973). Thus, Erdkinder leaders and teachers should encourage all students to help one another, reinforcing to students the idea that they are skilled, knowledgeable, and able to serve as a valuable source of help to others in the school.

\section{Role of Teachers}

The guidance provided by teachers and the relationships teachers form with students are critical to the success of Erdkinder students (Rathunde \& Csikszentmihalyi, 2005; Wentzel, 1998). In traditional schooling, students rarely receive help outside of formal lessons (Guthrie \& Davis, 2003), and teachers are often viewed as distant and judgmental (Rathunde \& Csikszentmihalyi, 2005; Wentzel, 1998). Instead of 
using lectures, teachers in modern Erdkinders facilitate self-directed projects in which pupils learn from one another throughout school hours and teachers are available for questions throughout the day and involved in a multitude of subjects (Montessori, 1973; Rathunde \& Csikszentmihalyi, 2005). Ideally, students will not feel self-conscious about asking any teacher for help in any subject, and this help will be readily available to them (Montessori, 1973). Teachers should engage with their students as equals and act as guides for learning, not as sovereigns.

\section{Need for Evaluation}

One issue facing Montessori secondary education is that no official governing body certifies or oversees Erdkinders. Commonly, the schools themselves shoulder the responsibility of proving to parents that they adhere to Erdkinder principles (North American Montessori Teachers' Association, 2015). Evidence suggests that Erdkinders are building positive work communities (Casquejo Johnston, 2016); however, there is a pervasive lack of evaluation in these schools due to a lack of tools capable of accurately evaluating the outcomes of this unique learning environment. Also, the Montessori community is resistant to traditional educational assessment methods, which it views as overly reliant on cognitive instruments (Pottish-Lewis, 2013). To gain the necessary insight for improvement, Montessori schools need evaluation methods and tools that can capture the social environment within their schools (Pottish-Lewis, 2013; Tornar, 2011).

\section{Social Network Research in Education}

This study used social network analysis (SNA) as the primary method of analysis to answer research questions because SNA provides a way to understand the patterns of academic assistance occurring within a school. Although the education field continues to recognize the value of using SNA to answer research questions, these techniques remain underutilized in $\mathrm{K}-12$ education research, particularly for the evaluation of programs and interventions with social goals (Akers, 2011; Daly, 2010; Scott, 2000). Generally, schools rely on traditional social science analyses to evaluate programs and plan interventions (de Laat, Lally, Lipponen, \& Simons, 2007). However, holistically oriented schools have difficulty using standard methods because these tools are not suited to examine social relationships. Further, inferential statistics do not describe students’ social context well (de Laat et al., 2007; Thomas, 2000).

The past two decades have provided a steady influx of research exploring the potential for SNA to innovate educational evaluation and classroom studies. For example, Martinez, Sher, Krull, and Wood (2009) integrated SNA with qualitative methods and inferential statistics to develop a nuanced interpretation of collaborative learning. Coburn and Russell (2008) found social network theory apt for determining how new district policies change teacher relationships. The benefits to using SNA in K-12 education settings are great, as SNA methodologies provide a clearer picture of the formal and informal workings of a school. These tools could also be key to determining if schools affect not only the cognitive outcomes of students but also the social outcomes. Thus, we intended to test the use of SNA to identify, describe, and evaluate the academic assistance networks within a Montessori school.

\section{Purpose}

The purpose of this study was to pilot a social network-based evaluation method to determine if a school committed to providing a whole-child approach to education was developing the supportive and egalitarian system it intended to build. By examining the academic assistance networks within a school, the study addresses the following research questions:

1. How cohesive are the academic assistance networks for English, math, social studies, science, and foreign language?

2. Who are the main sources of academic assistance in these networks? 
3. Does difference in self-perceived knowledge level predict assistance ties for each subject?

These research questions reflect the evaluative purpose of the study and demonstrate what a school adopting this methodology for evaluation purposes would examine as part of its evaluation. As the principles of inclusion and community responsibility are a key focus for the target school, we anticipated that the students would have very dense networks for each subject (i.e., English, math, social studies, science, and foreign language) and that difference in knowledge levels would predict the variance in assistance ties for all subjects. We also anticipated upperclassmen to be the most important sources of assistance because their higher level of education and extended experience in the Erdkinder setting may make them more inclined to help others.

\section{Methods}

To address the research questions of this study, we collected social network data from an Erdkinder that was interested in exploring new evaluation tools. The school is a small, private setting composed of 23 students and eight teachers. The students span four grade levels (i.e., grades 9, 10, 11, and 12) but learn in combined classrooms. The eight teachers are responsible for their own specialty subjects but share responsibility in teaching the school's five main courses (English, math, social studies, science, and foreign language). Preliminary interviews with school administrators indicated that students interact openly with peers and teachers. In other words, students talk to each other freely and work collaboratively on multiple projects throughout the school day. Students also address teachers spontaneously rather than awaiting direct instruction. However, administrators were concerned that only a few students provide academic assistance. Further, administrators were curious whether teachers provide help outside of their designated subjects. Administrators encourage teachers to assist with subjects outside of their specialty; however, observations of daily teaching caused administrators to wonder if this cross-subject help takes place.

\section{Network Survey and Data}

Working with the school's administration and board of directors, we designed the School Academic Assistance Survey (SAAS), a social network survey. This instrument asked students and teachers to name the individuals to whom they had provided help in five subjects: English, math, social studies, science, and foreign language. Thus, the instrument collected relationship data for five assistance relationships. A multigrid roster displayed the survey items, with one column for each subject. This style of network survey prevents cognitive overload and lessens the time needed to complete the survey when compared to openresponse questionnaires. The survey asked students and teachers to mark the name of (or endorse) anyone whom they helped at any time during the school day. However, the survey did not ask respondents to specify when or how often they helped because recalling these details is difficult for adolescents, and evidence suggests that respondents cannot recall patterns with a high degree of accuracy (Bernard, Killworth, \& Sailer, 1982; Borgers, Hox, \& Sikkel, 2003). This set of relational data will be referred to as the I-Help data.

The SAAS collected a second set of relationship data to increase the validity of the responses. Research indicates that some groups of students (particularly girls) will not be forthcoming about whom they help because of cultural expectations of modesty (Lent, Brown, \& Larkin, 1984; Pajares \& Schunk, 2001; Raby \& Pomerantz, 2015). To improve accuracy, therefore, the survey used a second multigrid roster to capture who provided help to the participants. The SAAS asked students and teachers to endorse the names of everyone who had helped them in each of the five subjects, identifying additional ties that respondents may have overlooked. This second roster also addressed missing data when participants did not complete the survey. This set of relational data will be referred to as the Helps-Me data. The I-Help data and the Helps-Me data collected from the survey captured the complete academic assistance network within the school and account for potential underreporting of ties.

To acquire the independent variables, the SAAS asked respondents to rate their perceived knowledge of a subject. The item "How would you rate your knowledge level in the following subjects?" collected responses using a Likert-type rating scale ranging from very low to very high, and determined the 
students and teachers who self-identified as the most and least knowledgeable. The descriptive data produced by this item determined whether perceived knowledgeableness predicts academic assistance ties. Similarly, at the request of the school and to address students' emotional well-being, the SAAS asked participants "How would you rate your comfort level with each of the following subjects?" The data from this item are included in the analyses discussed below but are not the focus of this study's research objectives.

The SAAS also used multiple-choice items to collect demographic data related to status and sex. Status indicated respondents' status as teacher or student, as well as students' grade level. This item yielded data needed to determine whether students and teachers assist others without regard to status, as Dr. Montessori intended (Kahn, 2011). Respondents' self-reported sex was a control variable in the analyses described below.

Coding. For the relational data collected from the I-Help portion of the SAAS, five adjacency matrices exist, one for each subject. As the survey asked respondents to indicate only whether or not a relationship existed, binary coding was used. For example, a value of 1 in the cell $i, j$ indicated that actor $i$ provided help to actor $j$. A value of 0 in cell $i, j$ indicated that actor $i$ did not provide help to actor $j$. We used the same procedures to code adjacency matrices for the Helps-Me portion of the SAAS. A value of 1 in cell $i, j$ indicated that actor $i$ was helped by actor $j$. A value of 0 in cell $i, j$ indicated that actor $i$ was not helped by actor $j$.

After coding, we compared the rows in the transpose of the Helps-Me matrices to the corresponding rows of the I-Help matrices. Any additional ties identified by the transpose of Helps-Me matrices were added to the actors' vector in the I-Help matrices. This step created the five network matrices this study used for data analyses (i.e., the academic assistance network matrices), in which a value of 1 in cell $i, j$ indicated that actor $i$ provided help to actor $j$, as endorsed by $i, j$, or both. Again, to acknowledge the welldocumented phenomenon of female students downplaying their importance in school, this study used both sets of relational data to create the assistance network. For participants who consented to be in the study but who did not complete the I-Help network items, the transpose of their column in the Helps-Me matrices filled their row in the I-Help matrices. Following the coding of the relational data, the analyses also included each respondent's responses to the knowledge and comfort scales, as well as their self-reported sex.

\section{Procedures and Analyses}

The study received approval from our institutional review board in April 2016. The process of gaining consent began 1 week before data collection, and students and teachers completed the pen-andpaper surveys during school hours. Usable network-survey data were acquired from 20 students and seven teachers, roughly $87 \%$ of the school population. The survey responses were then coded and entered into a spreadsheet, and respondents' names were recoded as pseudonyms. As detailed in the previous section, responses to the network questions were used to create the academic assistance network matrices used in the analyses.

Each academic assistance network matrix was input into UCINET 6.596 (Borgatti, Everett, \& Freeman, 2002), analytical software that specializes in SNA and that uses network matrices to calculate network measures and the strength of relationships. The program created one-mode network datasets for assistance in English, math, social studies, science, and foreign language. The respondents' descriptive variables were also input into UCINET to create a dataset of respondents' individual characteristics.

\section{Network Measures}

To answer the first research question (i.e., How cohesive are the academic assistance networks for English, math, social studies, science, and foreign language?), multiple measures assessed the degree to which the school was cohesive. For each subject's academic assistance network, we calculated network density. Network density is a measure of a network's interconnectedness and is determined by the 
proportion of relationships that do exist to the number that could possibly exist. Because Erdkinders stress open interaction and group work, the network ideally is markedly interconnected. The density measures determine which of the five subjects are most and least dense so that the school can target its efforts to the appropriate subjects when trying to increase student interaction. Given that this study was the pilot for future studies, this density measure acted as a baseline measure for future network analyses.

Reciprocity, which was acquired using the reciprocity procedure in UCINET, also shows the school's cohesion, indicating how often students and teachers reciprocate the assistance given to them by others in the network. Students who rated themselves on the survey as having a lower level of knowledge of a subject expectedly may be less able to reciprocate the help they receive, specifically from the students who rated themselves as having a higher level of knowledge. Although this outcome is likely, understanding the reciprocity in the networks is important, as the connections between students may decay over time if help is not reciprocated.

To address the second research question (i.e., Who are the main sources of academic assistance in these networks?), outdegree centrality determined which participants provided the most assistance to others for the various subjects. Outdegree centrality measures the number of outgoing ties in a person's network; in other words, how many other people to whom a student or teacher provided assistance. Outdegree centralization was also calculated for each subject's network because of the school administration's concerns that students may depend too much on assistance from a single person. Outdegree centrality assessed the degree to which each subject's network revolved around one person, indicating whether those concerns were justified.

\section{Multiple Regression Quadratic Assignment Procedures}

A series of multiple regression quadratic assignment procedures (multiple regression-QAPs) answered the third research question, (i.e., Does difference in self-perceived knowledge level predict assistance ties for each subject?). Multiple regression-QAPs are commonly used in social network studies; they provide a means of running multiple regressions using dyadic rather than individual data. Multiple regression-QAPs involve conducting permutations of potential dyadic pairs to determine if a variable has a significant effect on whether a relationship would be observed. As Montessori principles assert that moreknowledgeable students should provide more help than less-knowledgeable students (Kahn, 2011), this analysis was chosen to determine if knowledge level is, in fact, predictive of the variance in the school's assistance ties. The results of the multiple regression-QAPs were presented to the school as an indicator of whether highly knowledgeable students provide help to less-knowledgeable students. A multiple regression-QAP was performed using all five academic assistance networks as dependent variables. Thus, five procedures created models in which assistance in English, math, social studies, science, and foreign language were the dependent variables.

The independent variables for the multiple regression-QAPs comprised participants' self-reported knowledge level and comfort level in each of the five subjects. In each model, sex was a control variable for the likelihood that people would assist others of the same sex. Status (i.e., participant's grade level or standing as a teacher or student) also was an independent variable in all regression models to test whether sharing the same grade level or position as student or teacher affected assistance ties. As the analyses used in this study were a series of multiple regressions of dyadic data, these individual-level variables had to be transformed into dyadic variables that define a relationship. Thus, the sex of a participant became a dyadic variable that was defined by whether participants were of the same sex. School status was defined by the difference between a participant's grade level and the grade level of every other person in the network, as well as the difference between being a student and being a teacher. Comfort and knowledge levels became dyadic for the analyses by expressing each participant's knowledge- and comfort-level rating as the quantitative difference between the knowledge- and comfort-level ratings of every other person in the network. Transformations of variables were conducted for all participants' ratings of their knowledge and 
comfort levels for each subject, and the new dyadic variables were included in the regression model for each subject in addition to the dyadic variables for sex and status.

\section{Results}

\section{English Assistance Network Measures}

The English assistance network, as shown in Figure 1, had a density of .141, meaning that students and teachers reported participating in $14.1 \%$ of the assistance relationships that could exist in the network.

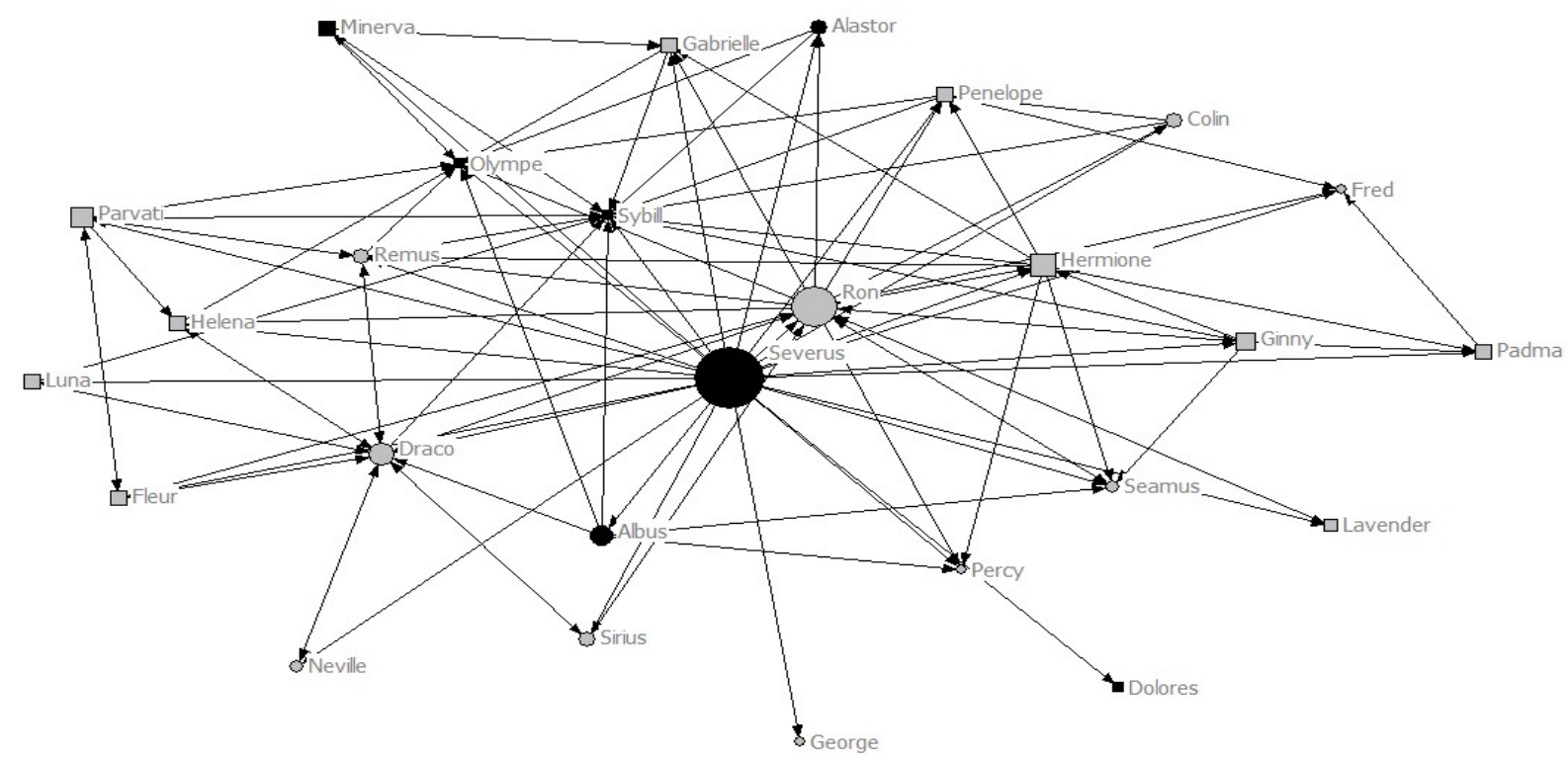

Figure 1. English academic assistance network. Teachers' names appear in black, and students' names appear in gray. Female subjects are represented as squares, and male subjects are represented as circles.

This percentage can be interpreted as low, as the subject school is a small school focused on collaborative work, and collaborative environments typically realize 30\% of the network ties possible (Borgatti, Everett, \& Johnson, 2013). However, it was not the lowest of the school's network densities, as Table 1 shows.

Table 1

Network Measures for the Five Academic Assistance Networks

\begin{tabular}{lrrcrc}
\hline \multicolumn{1}{c}{ Measure } & English & Math & Social studies & Science & $\begin{array}{c}\text { Foreign } \\
\text { language }\end{array}$ \\
\hline Density & .141 & .120 & .080 & .171 & .071 \\
Reciprocity & .242 & .333 & .250 & .387 & .240 \\
Average degree & 3.667 & 3.111 & 2.074 & 4.407 & 1.852 \\
Outcentralization & .892 & .675 & .436 & .862 & .325 \\
\hline
\end{tabular}

The measure for reciprocity in the network was .242, meaning that just over $24 \%$ of the assistance ties for English were reciprocated. The average degree for participants was 3.667, meaning students gave or 
received help from more than three others on average. Outdegree centralization was .892, meaning that the English network was highly oriented around one actor. These measures were unexpected, given that the school strives to be highly collaborative and encourages free interaction. Highly collaborative environments are expected to have more instances of reciprocity, a greater number of ties, and lower centralization (Borgatti et al., 2013). However, it is worth noting that these procedures are largely untested in secondary schools, particularly Montessori schools. Therefore, such networks have no established norms.

Table 2 displays the degree measures for each of the actors. The degree measure indicates that Severus, the English teacher, helped the greatest number of people in this network, with outgoing ties to 26 students and teachers. Student Ron followed, helping 16 other people. Science teacher Sybill received the most help from other teachers and students, getting help from 13 others. Foreign language teacher Olympe received help from 10 others. No graduating senior was among the most helpful actors for English.

Table 2

Actors' Outdegrees for the Five Academic Assistance Networks

\begin{tabular}{lrrrrr}
\hline \multicolumn{1}{c}{ Actor } & \multicolumn{4}{c}{ Network outdegree } \\
\cline { 2 - 6 } \multicolumn{1}{c}{ English } & Math & Social studies & Science & Foreign language \\
\hline Sirius & 2.0 & 4.0 & 2.0 & 5.0 & 1.0 \\
Luna & 2.0 & 3.0 & 0.0 & 1.0 & 1.0 \\
Ron & 16.0 & 1.0 & 1.0 & 3.0 & 0.0 \\
Parvati & 5.0 & 4.0 & 0.0 & 4.0 & 1.0 \\
Draco & 7.0 & 2.0 & 8.0 & 26.0 & 4.0 \\
Colin & 2.0 & 2.0 & 0.0 & 0.0 & 1.0 \\
Penelope & 3.0 & 2.0 & 2.0 & 2.0 & 4.0 \\
George & 0.0 & 4.0 & 1.0 & 4.0 & 2.0 \\
Lavender & 1.0 & 2.0 & 2.0 & 3.0 & 1.0 \\
Fleur & 3.0 & 5.0 & 2.0 & 6.0 & 2.0 \\
Padma & 2.0 & 2.0 & 1.0 & 3.0 & 1.0 \\
Seamus & 1.0 & 3.0 & 0.0 & 1.0 & 0.0 \\
Fred & 0.0 & 4.0 & 0.0 & 1.0 & 0.0 \\
Hermione & 7.0 & 4.0 & 5.0 & 2.0 & 2.0 \\
Percy & 0.0 & 0.0 & 0.0 & 0.0 & 0.0 \\
Remus & 3.0 & 4.0 & 0.0 & 1.0 & 2.0 \\
Neville & 1.0 & 1.0 & 0.0 & 1.0 & 0.0 \\
Ginny & 4.0 & 0.0 & 3.0 & 5.0 & 0.0 \\
Helena & 2.0 & 3.0 & 2.0 & 3.0 & 1.0 \\
Gabrielle & 2.0 & 2.0 & 1.0 & 1.0 & 1.0 \\
Olympe & 0.0 & 0.0 & 0.0 & 0.0 & 8.0 \\
Sybill & 0.0 & 11.0 & 1.0 & 25.0 & 1.0 \\
Alastor & 2.0 & 20.0 & 2.0 & 17.0 & 3.0 \\
Minerva & 3.0 & 1.0 & 1.0 & 3.0 & 2.0 \\
Albus & 5.0 & 0.0 & 8.0 & 2.0 & 0.0 \\
Severus & 26.0 & 0.0 & 13.0 & 0.0 & 0.0 \\
Dolores & 0.0 & 0.0 & 1.0 & 0.0 & \\
\hline Note. The & 5.0 & & & \\
\end{tabular}

Note. The names in the shaded rows are teachers' names. 


\section{Math Assistance Network Measures}

Figure 2 displays the math assistance network. This network had a density of .120, as shown in Table 1. The reciprocity for the network was .333, meaning that a third of the assistance ties for math were reciprocated. The average degree for actors was 3.111: the actors sought or provided math help to an average of about three people. Outdegree centralization was .675, meaning that math was not as oriented around one actor as English was.

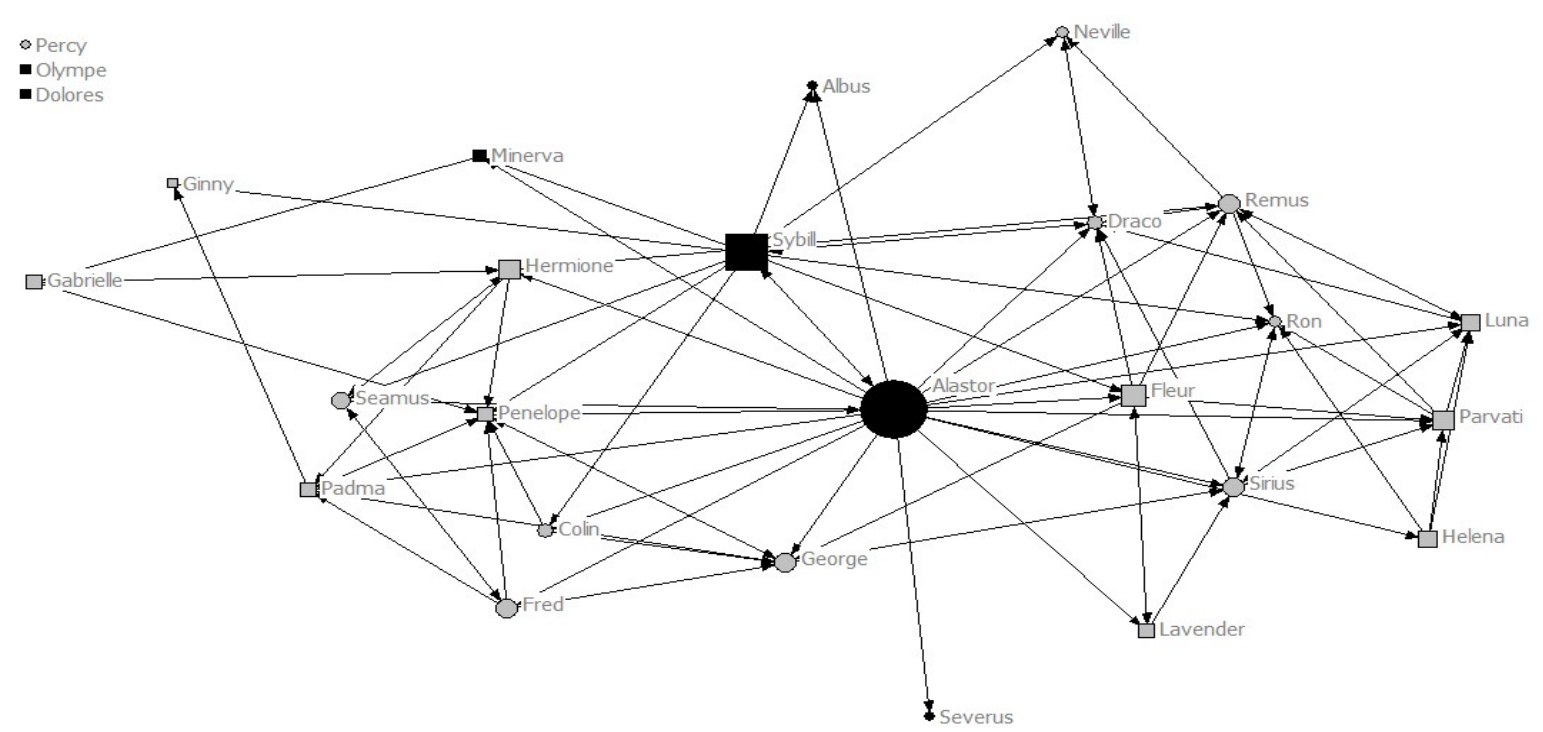

Figure 2. Math academic assistance network. Teachers' names appear in black, and students' names appear in gray. Female subjects are represented as squares, and male subjects are represented as circles.

Table 2 displays the degree measures for each of the participants. Alastor, the math teacher, and Sybill, the science teacher, assisted the greatest number of people in this network, at 20 and 11 peers respectively. Student Penelope assisted eight peers. No senior student was highly central in this network. Three participants (i.e., student Percy and foreign language teachers Olympe and Dolores) were isolates in this network and had no outgoing or incoming ties.

\section{Social Studies Assistance Network Measures}

Figure 3 displays the social studies assistance network, which had a particularly low density of .080 . The reciprocity for the network was .250, meaning that just over $25 \%$ of the assistance ties for social studies were reciprocated. The average degree for actors was 2.074: students and teachers gave or received help from about two people. Outdegree centralization was .436, showing that the social studies network was not notably oriented around one person. As shown in Table 2, English teacher Severus (who often doubles as the social studies teacher) had the greatest number of outgoing ties, having helped 13 people. Teacher Albus and student Draco helped eight others. The individual with the greatest number of incoming ties was Draco, who received help from six others. Again, senior students were not central, neither giving help to nor receiving help from a large number of peers. The network had two isolates: student Fred and foreign language teacher Olympe. 


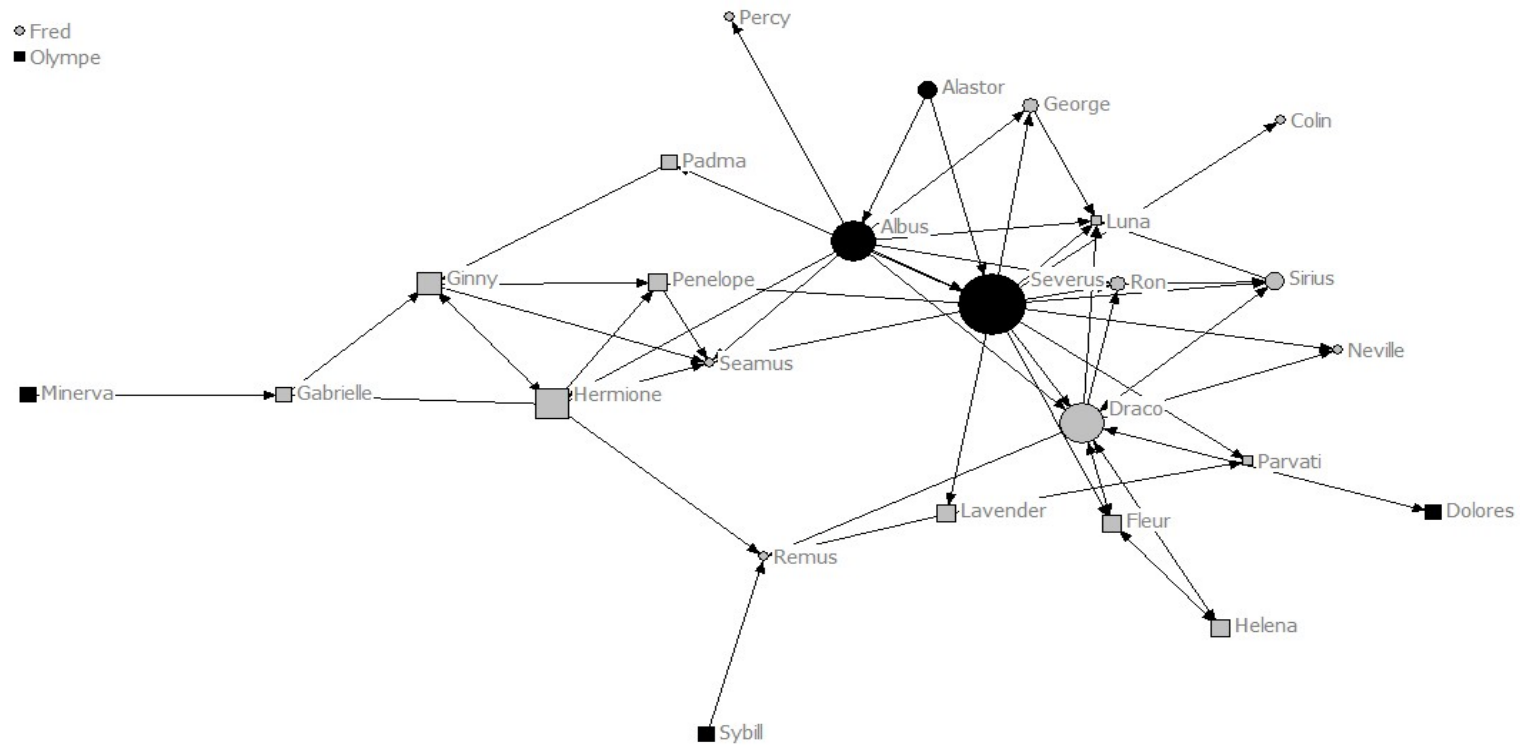

Figure 3. Social studies academic assistance network. Teachers' names appear in black, and students' names appear in gray. Female subjects are represented as squares, and male subjects are represented as circles.

\section{Science Assistance Network Measures}

Figure 4 displays the science assistance network which had the greatest network density of .171. The reciprocity for the network was .387, meaning that nearly $39 \%$ of the assistance ties for social studies were reciprocated. The average degree for actors was 4.407: students and teachers gave or received help to about four people. Outdegree centralization was .862, showing that the social studies network was more highly oriented around a single actor. As shown in Table 2, student Draco provided the most assistance, having helped 26 people. Science teacher Sybill helped 25 people. The participant who received the most assistance was also Draco, who was helped by 13 others. Again, senior students were not very central.

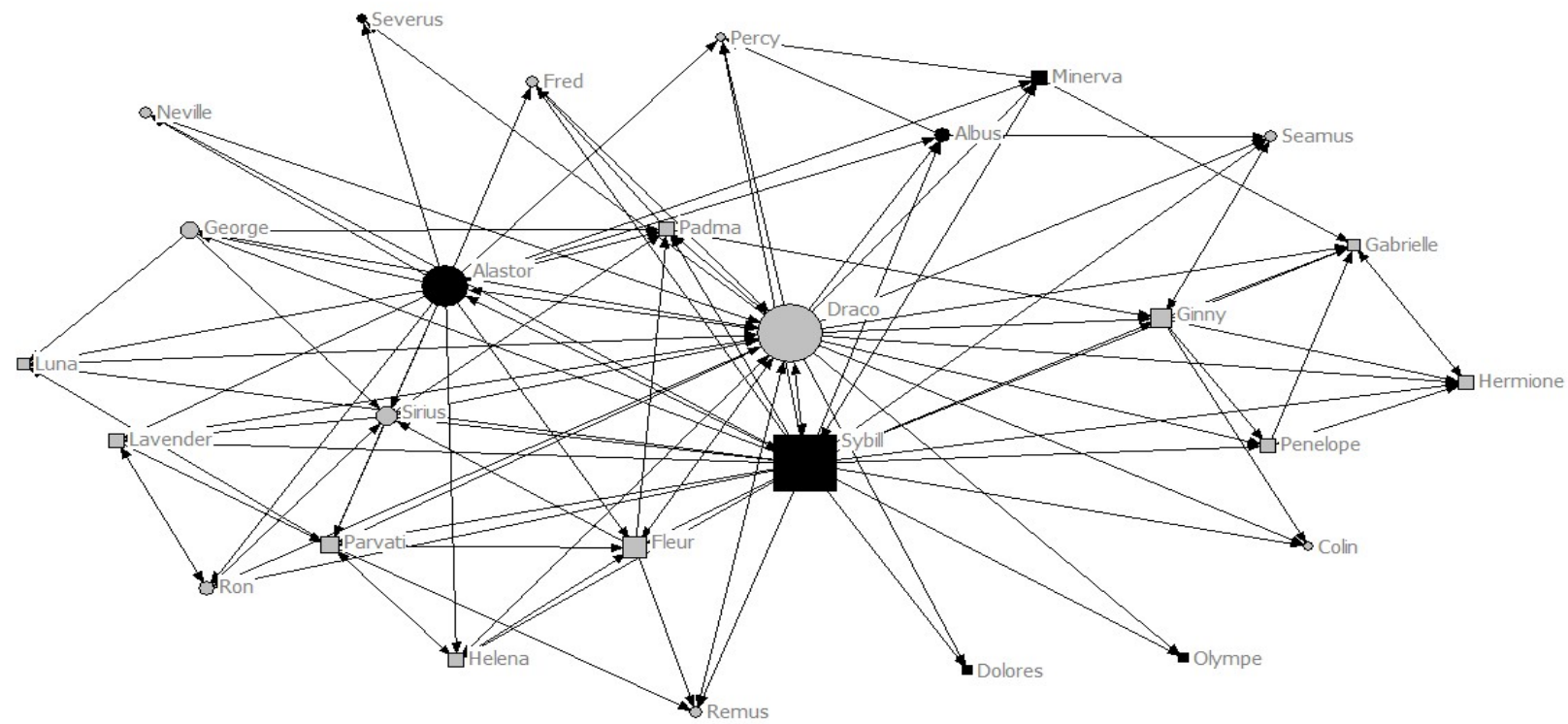

Figure 4. Science academic assistance network. Teachers' names appear in black, and students' names appear in gray. Female subjects are represented as squares, and male subjects are represented as circles. 


\section{Foreign Language Assistance Network Measures}

Figure 5 displays the foreign language assistance network. This network had the lowest network density of .071. The reciprocity for the network was .240, meaning that $24 \%$ of the assistance ties for foreign language were reciprocated. The average degree for actors was 1.852: students and teachers gave or received help to fewer than two people on average. Outdegree centralization was the lowest of all networks at .352, showing the foreign language network was not particularly oriented around a single actor. As shown in Table 2, foreign language teacher Dolores provided the most assistance, having helped 10 people. Olympe, the other foreign language teacher, helped eight others. The actor with the greatest indegree centrality was Draco at 13.0. Again, senior students were not very central. This network had four isolates who neither provided nor received help in this subject.

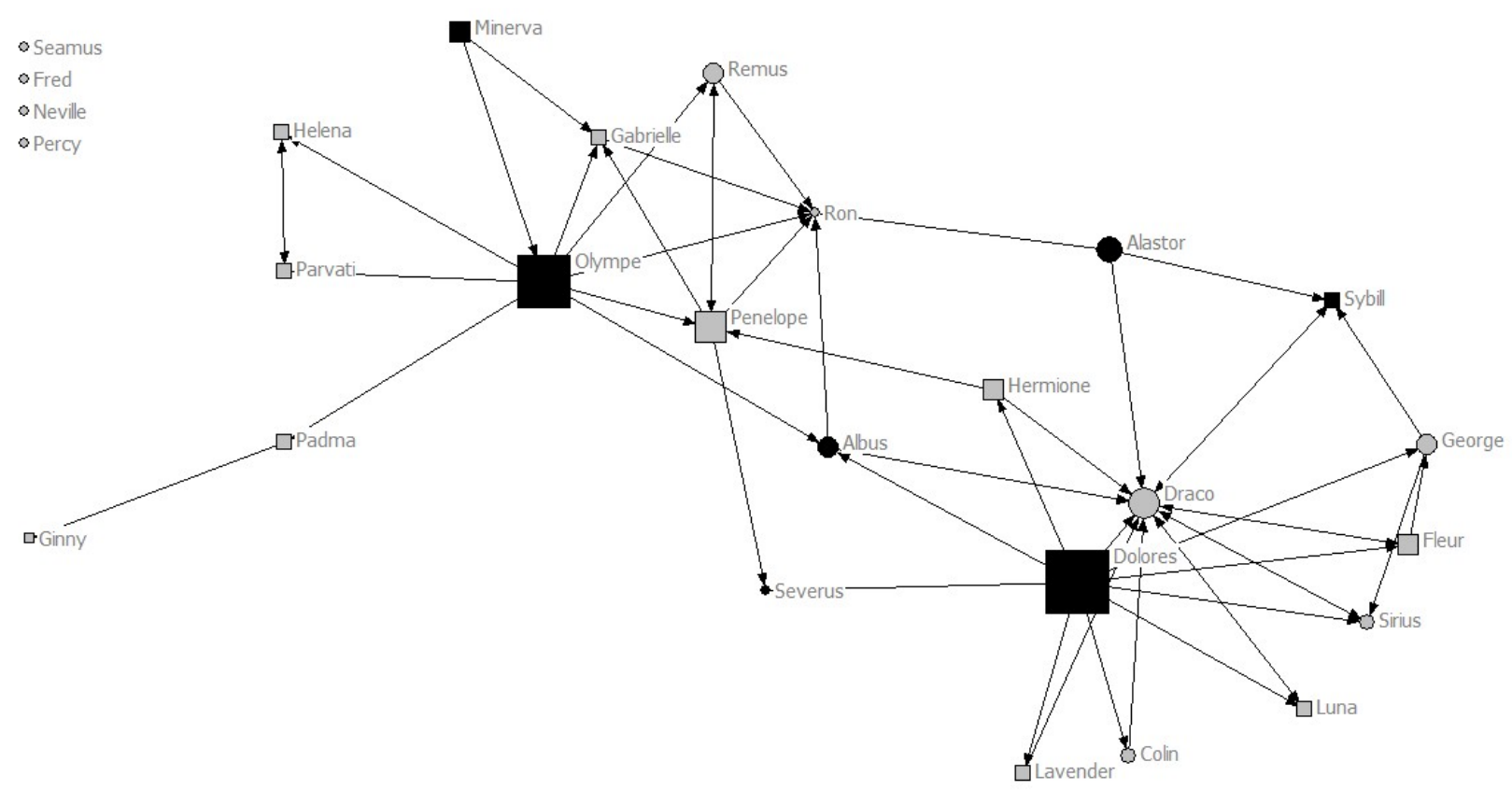

Figure 5. Foreign language academic assistance network. Teachers' names appear in black, and students' names appear in gray. Female subjects are represented as squares, and male subjects are represented as circles.

\section{Multiple Regression-QAP Results}

Multiple regression-QAPs included each of the academic assistance matrices as the dependent variable; thus, a model tested all five subjects. Each model included four independent variables: the same sex as matrix, the same status as matrix, the simple difference matrix for knowledge level in the respective subject, and the simple difference matrix for comfort level in the respective subject. Table 3 summarizes the results. 
Table 3

Multiple Regression-QAP Results

\begin{tabular}{|c|c|c|c|c|c|}
\hline Variable & English & Math & Social studies & Science & $\begin{array}{c}\text { Foreign } \\
\text { language }\end{array}$ \\
\hline sameSEX & .038 & $.012^{*}$ & .035 & $.047^{*}$ & .013 \\
\hline sameSTATUS & $.124^{* * *}$ & .075 & .006 & $.074^{*}$ & .044 \\
\hline diffEng know & .034 & & & & \\
\hline diffEng comf & .024 & & & & \\
\hline diffMath know & & .004 & & & \\
\hline diffMath comf & & .013 & & & \\
\hline diffSoc know & & & .003 & & \\
\hline diffSoc comf & & & .008 & & \\
\hline diffSci know & & & & .051 & \\
\hline diffSci comf & & & & .012 & \\
\hline diffLang know & & & & & $.025^{*}$ \\
\hline diffLang comf & & & & & -.008 \\
\hline$R$-squared & $.057^{* * *}$ & $.015^{*}$ & $.008^{*}$ & $.057^{* * *}$ & $.016^{* *}$ \\
\hline
\end{tabular}

${ }^{*} \mathrm{p} \leq .05 .{ }^{* *} \mathrm{p} \leq .01 .{ }^{* * *} \mathrm{p} \leq .001$.

\section{English Results}

The model had a significant $R^{2}$ of $.057(p<.001)$, explaining only $5.7 \%$ of the variance among the English academic assistance dyads. Differences in English knowledge did not have a significant effect on the expected number of cases of English assistance seen in 1,000 observations of individual $i$ helping individual $j$. The variable for participants' school status had a significant coefficient of .124. Thus, sharing the same grade level or position in the school means 124 more instances of $i$ helping $j$ in English are expected in 1,000 observations, compared to when the individuals do not share the same school status. Differences in English comfort level and sharing the same sex were not significant.

\section{Math Results}

The model had a significant $R^{2}$ of $.015(p=.01)$, explaining only $1.5 \%$ of the variance among the math academic assistance dyads. Differences in math knowledge did not significantly influence the math assistance observed in the network. Sharing the same sex did have a significant coefficient of .012. When individuals are of the same sex, 12 more instances of $i$ helping $j$ in math are expected in 1,000 observations, compared to when the individuals are not of the same sex. Sharing the same school status and differences in math comfort level were not significant.

\section{Social Studies Results}

The model had a significant $R^{2}$ of $.008(p=.05)$, explaining only $0.8 \%$ of the variance among the social studies academic assistance dyads. Differences in social studies knowledge did not significantly affect the social studies assistance network. Sharing the same school status, sharing the same sex, and differences in social studies comfort level were not significant. 


\section{Science Results}

The model had a significant $R^{2}$ of .057 ( $p<.001$ ), explaining only $5.7 \%$ of the variance among the science academic assistance dyads. Science knowledge did not significantly influence the assistance ties observed, indicating that differences in science knowledge did not predict the number of science assistance cases observed in the network. Being of the same sex was significant in the model. Sharing the same sex means that 47 more cases of $i$ helping $j$ in science are expected in 1,000 observations. The coefficient for school status also was significant. Sharing the same school status means that 74 more cases of $i$ helping $j$ in science are expected in 1,000 observations. Differences in levels of science knowledge level and science comfort were not significant.

\section{Foreign Language Results}

The model had a significant $R^{2}$ of $.016(p=.005)$, explaining only $1.6 \%$ of the variance among the foreign language academic assistance dyads. The coefficient for difference in foreign language knowledge was significant, indicating that foreign language knowledge predicted the number of foreign language assistance cases observed. Therefore, with every one-unit increase in difference between two individuals' foreign language knowledge, 25 more cases of $i$ helping $j$ in foreign language are expected in 1,000 observations. The coefficient of .025 means that for every one-unit increase in difference in foreign language knowledge, the dependent variable will be .025 unit higher on average. Differences in foreign language comfort level, sharing the same sex, and sharing the same school status were not significant.

\section{Discussion}

The purpose of this study was to pilot a social network-based evaluation method to determine if an Erdkinder school was developing the supportive and egalitarian system it intended to build. To answer the first research question (i.e., How cohesive are the academic assistance networks for English, math, social studies, science, and foreign language?), we collected network data and acquired various network measures. The densities for all five academic assistance networks were lower than school administrators expected, given the school's small size and focus on collaboration. The science assistance network had the highest density measure at .171, while the foreign language network had the lowest at .071. Although no standard exists for the appropriate density for a Montessori school, administrators had hoped to see a density measure of at least .3, which is a more common value for collaborative organizations (Borgatti et al., 2013). The reciprocity measures indicate that most assistance ties were not reciprocated. Again, science had the highest measure at .387. Although Montessori principles explain why some students are less able to reciprocate the help they receive (Kahn, 2011; Montessori, 1973), the target school prefers students and teachers to be more involved with one another. These results show that the school is not as cohesive as administrators would like it to be, especially considering that some networks revealed isolated individuals who neither provided nor received help. We recommend that administrators encourage students to help each other more to achieve the desired close-knit, supportive environment. Foreign language has the most pressing need for intervention, as it had the lowest cohesion measures. The school may want to consider having these classes follow the example of the science classes by assigning foreign language group projects similar to ongoing science projects. These projects may give peers more opportunities to collaborate and to assist each another.

Regarding the second research question (i.e., Who are the main sources of academic assistance in the networks?), outdegree centralization and actors' outdegree centrality were calculated for each academic assistance network. For all subjects, designated subject teachers had the highest outdegree centrality and thus were the most important source of academic assistance in the networks. While this is expected in a traditional high school, students are expected to take the lead in Montessori schools, with teachers acting as supports (Rathunde \& Csikszentmihalyi, 2005). Therefore, we recommend that the school have teachers relinquish some control over the assistance they provide and remind students of the value of their help to others. The school may also benefit from asking students about the challenges of giving and receiving help; 
such an investigation may yield additional solutions. Among students, none of those with the highest outdegree centrality was a senior. Therefore, the school does not lose its most prolific sources of help to graduation. The outdegree centralizations for English and science were high, meaning that these networks depend heavily on one actor, likely because a single teacher or student provided most of the assistance. Encouraging students to help each other through peer mentoring or study groups may alleviate this issue.

Regarding the third research question (i.e., Does difference in self-perceived knowledge level predict assistance ties for each subject?), results for the series of multiple regression-QAPs showed that differences in perceived knowledge level were significant only for the foreign language network. However, even in this model, the explained variance was very low. The results of these analyses suggest that individuals do not display the assistance patterns expected under Montessori guidelines (Kahn, 2011), as perceived knowledge does not predict providing assistance to others. This may be because students relied heavily on subject teachers for help, students and teachers helped each other with little regard for their own talents, or students and teachers over- or underrated their own knowledge. We also recommend that school administrators work with students and teachers to recognize the unique talents and specific needs of both cohorts, as well as reinforce the responsibility members of each group have to share their talents with others. This goal could be reached via mentoring or other projects specifically oriented to students' talents and interests.

The multiple regression-QAPs also uncovered in English and science that being of the same role in the school—and for students, the same grade-level—was predictive of providing more assistance. Because the school aspires to be egalitarian and students should be helping one another regardless of their grade level, this preference for helping peers should not be present. In addition, the school should consider setting up multigrade peer partnerships and encouraging teachers to seek help from students. These strategies will encourage students to work more with students of other grade levels and will foster student independence.

\section{Conclusions}

This study was a pilot for using SNA to evaluate an Erdkinder; it provides a framework for other Montessori schools to evaluate the academic assistance networks in their schools. The techniques used in this study yielded valuable information for the target school's administration, showing that these concepts are applicable and appropriate for assessing this type of educational environment. The analyses described here show that the school successfully adheres to Montessori principles in some respects, such as with students helping teachers. However, there are also areas that may require attention. For example, school administrators could encourage students to rely less on subject teachers for assistance, and moreknowledgeable students should take on the responsibility of helping less-knowledgeable students. In identifying this result, we quantitatively confirmed school administrators' concerns about students' helping behaviors and provided evidence that the lack of help being provided is an issue that needs to be addressed.

One of the most positive aspects of this study is that it demonstrates how Montessori school leaders can identify the academic assistance networks already present in their schools, enabling schools to determine areas of strength and needs for improvement. Further, this method allows schools to identify individuals who are not very connected to the academic assistance networks and who may benefit, academically and socially, from becoming more closely connected to the school community. The possible implications for student academic success and possible reductions in negative social behaviors such as bullying and negative personal behaviors such as self-harm are worth examining at some point in the future (Bond et al., 2007; Langille, Asbridge, Cragg, \& Rasic, 2015; O’Brennan \& Furlong, 2010). Erdkinder administrators who are interested in the academic assistance networks present in their schools can implement a survey similar to this one and can conduct a similar analysis. The research questions in this study demonstrate how administrators can determine closeness in their school.

The implications for a school implementing the method described in this study go beyond identifying strengths and weaknesses in a school. Schools could use the data collected and the analysis 
results to market themselves to prospective students and families. Schools could also use the data and outcomes in accreditation reporting and in grant applications.

Furthermore, implementing this method demonstrates how helpfulness, an aspect of the Montessori valorization process (Donahoe, 2010), can be quantitatively measured and evaluated within a school setting. For this analysis, helpfulness is the action of providing academic assistance, although the concept of helpfulness in an Erdkinder likely goes far beyond this one strategy. For example, helpfulness could refer to a student assisting another student with cleaning a classroom space or practicing for an extracurricular, such as theater or baseball. While the reduction of this concept to academic assistance omits these other forms of helpfulness and the strategy captures only a small component of the larger valorization process, the analysis begins to provide a means of measuring and quantitatively evaluating the valorization process. Additional work with the Erdkinder community and the inclusion of additional evaluation tools may lead to the development of a full Erdkinder evaluation system.

Although we worked to reduce the study's limitations, a few are worth noting. One limitation of this study is that a combination of two sets of network data was used to create the academic assistance networks. While using these two sets of data mitigated issues of students underrating their help to others for sociocultural reasons, the networks likely include multiple interpretations of help rather than a single idea. Future work will include investigating ways to gain an accurate network with the use of valued networks that indicate how often students and teachers provide help to one another.

\section{AUTHOR INFORMATION}

\section{†Corresponding Author}

R. Renee Setari ${ }^{\dagger}$ is a Metrics, Evaluation, and Research manager for the National Geographic Society and specializes in evaluating education programs. This research was conducted while she completed her doctorate in education at the University of Kentucky. She can be reached at rsetari@ngs.org.

Anthony Philip Setari recently received his PhD from the University of Kentucky.

\section{References}

Akers, K. S. (2011). Connections, paths, and explanations: A social network approach to investigating experiences of experiences of early childhood special education with the ECLS-K (Doctoral dissertation). University of Kentucky, Lexington. Available from https://uknowledge.uky.edu/gradschool_diss/165/

Barker, D. (2011). A historical look at Montessori’s Erdkinder. Communications: Journal of the Association Montessori Internationale, 1-2, 96-112.

Bernard, H. R., Killworth, P., \& Sailer, L. (1982). Informant accuracy in social network data V: An experimental attempt to predict actual communication from recall data. Social Science Research, 11, 30-66. https://doi.org/10.1016/0049-089X(82)90006-0

Bond, L., Butler, H., Thomas, L., Carlin, J., Glover, S., Bowes, G., \& Patton, G. (2007). Social and school connectedness in early secondary school as predictors of late teenage substance use, mental health, and academic outcomes. Journal of Adolescent Health, 40, 357.e9-357.e18. https://doi.org/10.1016/j.jadohealth.2006.10.013

Borgatti, S. P., Everett, M. G., \& Freeman, L. C. (2002). UCINET 6 for Windows: Software for social network analysis (Version 6.96) [Computer software]. Lexington, KY: Analytic Technologies.

Borgatti, S. P., Everett, M. G., \& Johnson, J. C. (2013). Analyzing social networks. Thousand Oaks, CA: SAGE. 
Borgers, N., Hox, J., \& Sikkel, D. (2003). Response quality in survey research with children and adolescents: the effect of labeled response options and vague quantifiers. International Journal of Public Opinion Research, 15(1), 83-94. https://doi.org/10.1093/ijpor/15.1.83

Casquejo Johnston, L. M. (2016). Examining Montessori middle school through a self-determination theory lens: A mixed methods study of the lived experiences of adolescents. Journal of Montessori Research, 2(1), 27-42. Retrieved from https://journals.ku.edu/jmr/article/view/4994

Coburn, C. E., \& Russell, J. L. (2008). District policy and teachers' social networks. Educational Evaluation and Policy Analysis, 30(3), 203-235. https://doi.org/10.3102/0162373708321829

Daly, A. J. (2010). Social network theory and educational change. Cambridge, MA: Harvard Education Press.

de Laat, M., Lally, V., Lipponen, L., \& Simons, R.-J. (2007). Investigating patterns of interaction in networked learning and computer-supported collaborative learning: A role for social network analysis. International Journal of Computer-Supported Collaborative Learning, 2, 87-103. https://doi.org/10.1007/s11412-007-9006-4

Donahoe, M. (2010). Liberty and hope for the adolescent: Valorization of the personality. Retrieved from the Cincinnati Montessori Secondary Teacher Education Program website: http://cmstep.com/wp-content/uploads/Valorization_of_the_Personality1.pdf

Forbes, S. H., \& Martin, R. A. (2004, April). What holistic education claims about itself: An analysis of holistic schools' literature. Paper presented at the annual conference of the American Educational Research Association, San Diego, CA. Retrieved from http://www.holistic-education.net/articles/research04.pdf

Grazzini, C. (2004). The four planes of development. The NAMTA Journal, 29, 27-61. Retrieved from http://www.montessori-namta.org/PDF/4planesofdevelopment.pdf

Gutek, G. L. (2004). Introduction: A biography of Montessori and an analysis of the Montessori Method. In G. K. Gutek (Ed.), The Montessori method: The origins of an educational innovation, including an abridged and annotated edition of Maria Montessori's The Montessori method (pp. 1-66). Lanham, MD: Rowman \& Littlefield.

Guthrie, J. T., \& Davis, M. H. (2003). Motivating struggling readers in middle school through an engagement model of classroom practice. Reading \& Writing Quarterly, 19(1), 59-85. https://doi.org/10.1080/10573560308203

Kahn, D. (2011). Eight pictures at an exhibition: A Montessori retrospective on the discovery of the adolescent. Communications, 1-2, 15-41.

Kahn, D., \& Pendleton, D. R. (2007). The whole-school Montessori handbook. Burton, OH: North American Montessori Teachers' Association.

Langille, D. B., Asbridge, M., Cragg, A., \& Rasic, D. (2015). Associations of school connectedness with adolescent suicidality: Gender differences and the role of risk of depression. Canadian Journal of Psychiatry, 60, 258-267. doi:10.1177/070674371506000604

Lent, R. W., Brown, S. D., \& Larkin, K. C. (1984). Relation of self-efficacy expectations to academic achievement and persistence. Journal of Counseling Psychology, 31, 356-361. http://dx.doi.org/10.1037/0022-0167.31.3.356

Martinez, J. A., Sher, K. J., Krull, J. L., \& Wood, P. K. (2009). Blue-collar scholars?: Mediators and moderators of university attrition in first-generation college students. Journal of College Student Development, 50, 87-107. doi:10.1353/csd.0.0053

Miller, J. P. (2010). Whole child education. Toronto, Canada: University of Toronto Press.

Miller, R. (1990). What are schools for? Holistic education in American culture. Brandon, VT: Holistic Education Press.

Montessori, M. (1973). From childhood to adolescence: Including Erdkinder and the function of the university. New York, NY: Schocken.

Montessori, M. (2011a). Principles and practice in education. Communications: Journal of the Association Montessori Internationale, 11-12, 50-60. (Reprinted from First Lecture, Institute of Medical Psychology, London, November 10, 1936.) 
Montessori, M. (2011b). The physical and psychological development of the adolescent. Communications: Journal of the Association Montessori Internationale, 1-2, 67-72. (Reprinted from the 34th Lecture given at the 23rd International Course, Amsterdam, 1938.)

Montessori, M. (2011c). The adolescent: A social newborn. Communications: Journal of the Association Montessori Internationale, 1-2, 73-78. (Reprinted from the 37th Lecture given at the 23rd International Course, Amsterdam, 1938.)

North American Montessori Teachers' Association (2015). Curriculum downloads. Retrieved from http://www.montessori-namta.org/Curriculum-Downloads

O’Brennan, L. M., \& Furlong, M. J. (2010). Relations between students' perceptions of school connectedness and victimization. Journal of School Violence, 9, 375-391. https://doi.org/10.1080/15388220.2010.509009

Pajares, F., \& Schunk, D. H. (2001). Self-beliefs and school success: Self-efficacy, self-concept, and school achievement. Perception, 11, 239-266.

Pottish-Lewis, P. (2013). Standardized tests: Help or hindrance. AMI/USA Journal, Winter, 3-8.

Raby, R., \& Pomerantz, S. (2015). Playing it down/playing it up: girls' strategic negotiations of academic success. British Journal of Sociology of Education, 36, 507-525. https://doi.org/10.1080/01425692.2013.836056

Rathunde, K., \& Csikszentmihalyi, M. (2005). Middle school students' motivation and quality of experience: A comparison of Montessori and traditional school environments. American Journal of Education, 111, 341-371. http://www.jstor.org/stable/10.1086/428885

Scott, J. (2000). Social network analysis. Los Angeles, CA: SAGE.

Standing, E. M., \& Havis, L. (1998). Maria Montessori: Her life and work. New York, NY: Plume.

Thomas, S. L. (2000). Ties that bind: A social network approach to understanding student integration and persistence. Journal of Higher Education, 71, 591-615. http://www.jstor.org/stable/2649261

Tornar, C. (2011). The secret of adolescence. Communications: Journal of the Association Montessori Internationale, 1-2, 113-120.

Wentzel, K. R. (1998). Social relationships and motivation in middle school: The role of parents, teachers, and peers. Journal of Educational Psychology, 90, 202-209. http://dx.doi.org/10.1037/0022$\underline{0663.90 .2 .202}$ 